\title{
SOCIOLOGY
}

\section{ПРОБЛЕМА СОЦИАЛЬНОГО НЕРАВЕНСТВА В КОНТЕКСТЕ ФОРМИРОВАНИЯ В РОССИИ "ОБЩЕСТВА РАВНЫХ ВОЗМОЖНОСТЕЙ"}

\author{
Ю. В. Колин, докторант \\ Южный Федеральный государственный университет, г. Ростов-на-Дону, Россия
}

DOI: https://doi.org/10.31435/rsglobal_wos/31072019/6605

\section{ARTICLE INFO}

Received: 22 May 2019

Accepted: 14 July 2019

Published: 31 July 2019

\section{KEYWORDS}

social inequality, social elevator, human capital, paternalistic policy, civil society, model of catching up development, social polarization in Russia, "society of equal opportunities"

\begin{abstract}
Global trends show the importance of social inequality for the prospects for social growth. The danger to Russian society of the process of social polarization has been revealed.

The lack of attention on the part of the authorities to the problem of social inequality and the formation of an "equal opportunity society" in Russia has been determined. The importance of developing human capital to address catch-up development and the formation of an "equal opportunity" society has been substantiated
\end{abstract}

Citation: Ю. В. Колин. (2019) Problema Social'nogo Neravenstva v Kontekste Formirovaniya v Rossii "Obshchestva Ravnyh Vozmozhnostej". International Academy Journal Web of Scholar. 7(37). doi: 10.31435/rsglobal_wos/31072019/6605

Copyright: (ㄷ 2019 Ю. В. Колин. This is an open-access article distributed under the terms of the Creative Commons Attribution License (CC BY). The use, distribution or reproduction in other forums is permitted, provided the original author(s) or licensor are credited and that the original publication in this journal is cited, in accordance with accepted academic practice. No use, distribution or reproduction is permitted which does not comply with these terms.

Введение. Значимость проблемы социального неравенства в контексте обеспечения общественной стабильности и экономического роста в мире неоднократно подчеркивалась исследователями (Piketty, 2014; Kueger, 2012), а также политическими функционерами самого различного уровня (Blair, 1994; Lagarde, 2015; Obhama, 2012), рассматривающих проблему социального неравенства как угрозу современной демократии. Французский исследователь Т. Пикетти полагает, что проблема социального неравенства становится все более актуальной в современном мире (Piketty, 2014). Распределение ключевых социально-экономических показателей показывает их сильную связь со структурой неравенства в странах, высокий уровень социального неравенства служит препятствием для развития потребительского рынка и внутреннего спроса, что ограничивает экономический рост (Григорьев, Павлюшина, 2018, с.29, 35).

Международное сообщество признало важность проблемы социального неравенства, включив ее в соглашение ООН 2015г. по Целям устойчивого развития. Российское правительство подписало данное соглашение. Исследования МВФ показывают, что для общественного роста важен характер распределения доходов: повышение уровня благосостояния бедных и среднего класса на 1\% дает повышение темпов роста ВВП на 0,38\% пункта (Григорьев, Павлющина, 2017, с.60). Некоторые экономисты утверждают о пользе умеренного социального неравенства для общественного роста (Kuznets, 1955). В то время как другая группа исследователей полагает, что неравенство в мире достигло стадии, когда оно перестало быть эффективным и превратилось в серьезную помеху развитию (Stiglitz, 2012; Григорьев, Павлюшина, 2018).

Для высокого общественного роста нужны возможности для карьеры, сильные социальные лифты в обществе. Нобелевский лауреат Дж. Стиглиц утверждает, что в обществах с высоким уровнем социального неравенства не может быть эффективного функционирования его систем, так 
как высшая социальная группа сосредотачивает в своих руках слишком большое количество власти и действия общества начинают быть направлены на преимущественную реализацию интересов данных групп, а не своих собственных (Стиглиц, 2016). Эксперты ОЭСР полагают, что значительное отставание в росте доходов низших социальных групп от высших в настоящее время является общемировой тенденцией (Outlook, 2014; OESD, 2016).

В России проблема социального неравенства признается как в майских указах президента Путина (2012), так и правительством (Медведев, 2010), но конкретной стратегии, в рамках комплексного подхода к решению данной проблемы, пока не выработано (Григорьев, Павлюшина, 2017; Кривякина, 2017; Куликов, 2017).

Проблема общественной поляризации и социального неравенства в России.

В СССР уровень социального неравенства, разрыв между доходами высших и низших социальных групп был одним из самых низких в мире (при общем низком уровне данных доходов): 4 раза - в СССР и примерно 5,5-6 раз в европейских странах, в то время как в США данный разрыв достигал 15 раз (Данканич, 2011).

В настоящее время, по разным оценкам, разрыв между высшими и низшими социальными группами в российском обществе достигает 15 раз, при сохраняющейся тенденции сокращения располагаемых доходов низших групп населения и увеличения концентрации доходов в высшей социальной группе (Данканич, 2011; Григорьев, Павлющина, 2017), что во многом определяется структурой собственности, сложившейся на данный момент в России.

По данным исследователей, в высшей социальной группе, составляющей $3 \%$ населения сосредоточено около 90\% всей собственности и финансовых средств РФ, что превосходит показатели 1905 года (Узбекова, 2016; Шаповалов, 2019; Ремизов, 2016; Данканич, 2011).

Доля богатства, которой владеет верхний дециль в России (фактически $1 \%$ ) - 86\%, в Бразилии $-73 \%$, в США - 75\%, в Великобритании - 54\% (Rajan, 2004). Аналитики утверждают об избыточности уровня социального неравенства в России и его устойчивой структуре с начала 2000-х гг., при этом важное значение для России имеет и региональное неравенство (Салмина, 2014).

На долю $10 \%$ самых обеспеченных граждан приходится $82 \%$ всего личного богатства в России, согласно данным отчета о мировом благосостоянии Global Wealth Report (2018), подготовленного банком Credit Suisse. По уровню концентрации богатства Россия впереди США, где на долю 10\% самых обеспеченных граждан приходится 76\% общих личных доходов в стране. В Китае 10\% самых обеспеченных граждан обладают $62 \%$ совокупных личных доходов населения (Новопрудский, 2019).

В российском обществе продолжаются процессы социальной поляризации: вопреки существующей тенденции общего снижения располагаемых доходов граждан (Кудрин, 2019), согласно исследованию Global Wealth Report (2016), которое проводит банк Credit Suisse, РФ вышла на третье место в мире (96 человек) по количеству долларовых миллиардеров, уступая только США и Китаю (Седлов, Аникина, 2016.( Эти данные показывают слабую корреляцию роста доходов высшей социальной группы с ростом доходов низшей социальной группы, где последние годы фиксируется снижение реально располагаемых доходов (Кудрин, 2019; Шевкунова, 2019).

В России значительно количество населения (12\%), живущего ниже прожиточного минимума (Кудрин, 2019), товары краткосрочного пользования, в основном продукты питания занимают в среднем 49,1\% в структуре личных доходов российского населения (Григорьев, Павлюшина, 2018: 45), снижение количества трудоспособного населения (Санги, 2018) и низкий процент представителей среднего класса, являются факторами социальной нестабильности (Шевкунова, 2019).

Без преодоления глубинных социальных разрывов, развития социальной системы в направлении большей открытости и мобильности, основным бенефициаром российской модернизации и общественного роста становится закрытая высшая группа российской бизнесэлиты ( $3 \%$ российского населения), владеющей в настоящий момент $90 \%$ всей российской собственности (Шаповалов, 2019), что создает условия для нестабильности российского общества.

Тенденции социальной поляризации накладываются на недостаточный уровень развития образования и здравоохранения: в рейтинге национальных систем высшего образования (2017) по версии международной сети университетов Universitas 21 Россия занимает 33-е место. Согласно данным медицинского журнала The Lancet на 2016 год, Россия располагается на 119 месте среди стран мира в рейтинге здоровья населения и на 123 месте в мире (2016) по продолжительности жизни населения (Средняя продолжительность жизни по 
странам мира: мужчины, женщины и оба пола, Статистический портал: статистика населения URL: www.statdata.ru/prodolzhitelnost-zhizni-v-stranah-mira).

Сформировавшись в первые годы после распада СССР, в российском обществе с 2000-х гг. сохраняется ригидность структуры социального неравенства (Григорьев, Павлюшина, 2017). Несмотря на уменьшение возможностей динамичного общественного роста вследствие социальных диспропорций, в России отсутствует национальная программа сокращения социального неравенства.

Проблема социального неравенства в контексте реализации модели "догоняющего
развития".
В настоящее время наблюдается тенденция увеличения разрыва между высокоразвитыми и среднеразвитыми странами за исключением Китая (Григорьев, 2018). Данные тенденции способствуют формированию однополярного мира в долгосрочной перспективе. Для реализации модели догоняющего развития, технологического рывка, который намеревается произвести Россия, необходимо учитывать опыт стран, уже успешно реализовавших данную модель.

Как полагают исследователи (Григорьев, Павлюшина, 2018, 46), догоняющее развитие в терминах кластерного подхода подразумевает комплексный переход всей системы институтов на более высокий уровень при одновременном увеличении подушевого дохода в среднем примерно вдвое (характерный разрыв между кластерами), экономика должна расти с большим преимуществом над остальными странами, причем с поправкой на рост населения. В настоящее время межстрановое неравенство сохраняет свое постоянство (за исключением Китая).

Уровень социального неравенства внутри стран также остается примерно постоянным, однако благодаря государственной программе борьбы с социальной поляризацией, уровень социального неравенства снижается последние 20 лет в Таиланде и Малайзии (Григорьев, 2018). В Китае борьба с социальным неравенством закреплена на политическом уровне, например, в Китае на 8 съезде КПК (2012) премьер Госсовета КНР Л.Кэцян выделил содействие социальной справедливости в качестве приоритетной линии развития (Григорьев, 2018; Сюй Яньли, 2006).

Единичные успешные случаи догоняющего развития в СССР (Moorsteen, 1962; Harrison, 1999) и в Китае (Григорьев, 2018) - имеют некоторые общие черты: масштабная активизация социальных лифтов при определяющей роли государственной политики, позволившей массам из низших социальных групп достичь уровней среднего класса (в рамках конкретного общества) по показателям качества и уровня образования, социальной защиты и способности достичь высших статусных позиций в социальной системе.

Максимальная концентрация собственности, доходов и экономической власти в рамках высшей узкой закрытой социальной группы делает российскую социальную систему неустойчивой, что отражается в гораздо более высоком уровне социального неравенства по сравнению с европейскими странами (Григорьев, 2018) и уменьшает "окно возможностей" для реализации модели "догоняющего развития".

Развитие человеческого капитала, производства и социальной сферы имеет общую основу в сокращении социальной поляризации и развитии социальной системы российского общества в направлении большей открытости, сбалансированности и динамичности. Важно также в контексте снижения социальных барьеров развитие политической системы, повышение ее прозрачности и сбалансированности.

Несмотря на различия между моделями "догоняющего развития" их объединяет решающая роль государства в формировании патерналистской политики, планировании перспективных сфер развития, позволившего организовать значительное количество качественных рабочих мест, создать эффективные социальные лифты.

Проблема заключается в построении социальной системы с открытыми условиями карьерных траекторий, когда государство, выполняя свою патерналистскую функцию совместно с частными коммерческими и некоммерческими структурами, оказывает масштабное социально-экономическое и культурное содействие развитию человеческого капитала и функционированию социальных лифтов.

Следует отметить центральную роль в современном мире стратегического планирования на государственном уровне, позволившего одним государствам реализовать свою социальную патерналистскую функцию и войти в элиту развитых стран, а другим реализовать "модель догоняющего развития", определив перспективные области развития. 
В данном отношении, как полагают исследователи (Клименко А., Барабашев А., 2016), в России необходимо развитие стратегического планирования на государственном уровне, учитывающее опыт западных стран.

Проблема формирования в России общества равных возможностей.

Проблему невозможности реализации представителями низших социальных групп своего потенциала можно отнести к разряду универсальных проблем, способствующих росту социального неравенства, общественной радикализации, мешающих общественному росту, формированию "общества равных возможностей" и проявляющих себя в настоящее время от движения "Occupy Wall Street" до движения "желтых жилетов" во Франции.

В своей работе "Социология революции" П.Сорокин полагал, что причиной как Февральской, так и Октябрьской революции была неспособность низших социальных групп реализовать свои потребности, человеческий потенциал в силу сословной структуры российского общества (Сорокин, 2005(. Проблему социального неравенства можно интерпретировать в терминах человеческого капитала: как низкую способность социальной системы стимулировать развитие человеческого капитала и абсорбировать общественный потенциал.

Ограничения развития человеческого капитала вследствие несбалансированности социальной структуры, сфер труда, образования и сферы здравоохранения сокращают общественный потенциал для роста и развития, что, как полагают исследователи, создает условия для общественной нестабильности (Novokmet Filip, Thomas Piketty, Gabriel Zucman, 2017).

Поляризация российского общества находится в русле общемировой тенденции поляризации мирового богатства (Тома Пикетти. 2014), однако капиталистическое общество в России гораздо более молодое, несформировавшееся, несбалансированное и нестабильное, чем на Западе.

В России концепция формирования "общества равных возможностей" в настоящее время находится в рамках дискурса критики эгалитаристских концепций и наследия "тоталитарного прошлого". Утверждения о том, что реализация эгалитаристских концепций может быть свидетельством не обращения к прошлому, а путем к будущему динамичному развитию России непопулярно в среде исследователей.

Актуальности теме "равенства возможностей" придает также традиционно высокое значение ценностей социальной справедливости в системе ценностей российского общества, что, как полагают исследователи, влияет на оценку российским обществом перспектив своего широкого участия в российской модернизации в контексте понимания еe конечных бенефициаров (Деньгуб, 2004; Смольников, 2013; Демченко, 2018).

Уровень социального неравенства есть один из основных показателей избыточной иерархичности, социальной закрытости, ограниченности возможностей вертикальной социальной мобильности и способности социальной системы генерировать и абсорбировать человеческий капитал.

Проблема социального неравенства в контексте недостаточности вертикальной социальной мобильности есть показатель недостаточности развития рынка труда, сферы образования, служит индикатором низкого уровня развития "общества равных возможностей" в целом.

Формирование в России капиталистического общества идет неравномерно, акцент на фундаментальные капиталистические принципы преобладает над развитием социальной сферы, формированием компенсаторных механизмов, нивелирующих в развитых западных странах в определенной степени неравенство и несправедливость капитализма.

Компенсаторные механизмы способствуют формированию более социально ориентированной общественной модели, более справедливому распределению доходов, ограничению социального расслоения, повышению качества образования и здравоохранения для низших социальных групп, что в целом способствует повышению качества жизни и увеличения продолжительности жизни населения (OESD, Better Life Index).

Для стратегических позитивных общественных изменений и эффективной модернизации необходим высокий уровень вертикальной социальной мобильности и обратной связи между населением и властью.

По данным исследователей, существует прямая корреляция между темпом общественного развития и степенью открытости общественной системы, доступностью высших статусных позиций для выходцев из низших социальных групп (Шкаратан, 1987; Шкаратан, Ястребов, 2011). Чем больше закрытость общественной системы и меньше возможностей выходцам из низших социальных групп реализовать свой потенциал, тем меньше потенциал 
общественного роста, темп и уровень развития общества. В советском обществе существовал принцип позитивной дискриминации, когда преимущественное право социального продвижения имели выходцы из социальных групп рабочих и крестьян (Новосельцева,2004).

По мнению исследователей (М.Восленский, 1984, Назаров, 1990), одной из основных проблем позднего СССР, приведших к его распаду - это сокращение вертикальной социальной мобильности и постепенное превращение высшей советской элиты в закрытую касту.

В настоящее время в российском обществе формируется закрытая сложноиерархированная социальная структура, где существуют значительные ограничения вертикальной социальной мобильности. Индикатором служит закрытость и крайнее социальное расслоение российского общества, превышающее по степени распределения доходов между высшей и низшей социальной группой аналогичные показатели Восточной Европы почти в два paзa (Novokmet Filip, Thomas Piketty, Gabriel Zucman, NY, 2017// http://www.piketty.pse.ens.fr).

В советском обществе по идеологическим и социально-экономическим соображениям обеспечения всеобщей занятости и развития производства, - потребность в развитии человеческого потенциала существовала, несмотря на все гигантские диспропорции советского строя.

Трансформационный переход России от социалистического к капиталистическому обществу привел к значительным деформациям социальной системы, разрушению большинства социальных лифтов, функционирующих в советском обществе. Если в СССР большинство населения в рамках социальной динамики между поколениями, отмечало улучшение своего социально-экономического и образовательного статуса, то в современной России такой однозначно положительной динамики не существует (Шкаратан, 2011). По данным за 1983 год, среди респондентов в возрасте 50-59 лет 82,1 \% имели социально-профессиональный статус выше, чем их родители, среди респондентов 40-49 лет - $74 \%$, а среди 30-39 лет - 67\%, при этом данные показатели примерно идентичны как для мужчин, так и для женщин, что служит примером женской эмансипации в советском обществе (Шакаратан, 1987:88).

Картина социального неравенства, распределения различных социальных групп в социальной структуре по параметрам, включающим, в том числе уровень дохода, дает ответ на вопрос о социальных группах, являющихся основными бенефициарами совокупного общественного дохода и делает однозначным также ответ на вопрос о долгосрочных перспективах общественного роста в рамках данной социальной модели.

Уровень социального неравенства является индикатором того, что в России отсутствует эффективная политика по организации функционирования социальных лифтов, а в современной российской социальной системе массовая потребность в функционировании вертикальных социальных лифтов отсутствует в противоположность огромной потребности в функционировании социальных лифтов со стороны общества. В сфере частного бизнеса, науки, армии и т.Д., потребность в социальных лифтах существует, но их функционирование носит не столько общегосударственный, сколько частный и ограниченный характер при отсутствии в своей массе прозрачных общегосударственных критериев их функционирования.

Получив при распаде СССР огромный культурный и экономический капитал, Россия получила значительную базу для динамичного развития, однако значительная часть доставшегося новой России по наследству от СССР человеческого капитала была потеряна (Мухаметшина, 2016).

По мнению некоторых исследователей (Григорьев, 2016), "утечка мозгов", потеря Россией своего человеческого капитала вследствие эмиграции, невозможности высококвалифицированными работниками реализовать свой потенциал, стала одной из самых ощутимых потерь России с момента распада СССР, серьезно ограничивших ее потенциал общественного роста.

В современной России социальные лифты функционируют значительно менее эффективно, чем в советской России и уровень вертикальной мобильности в России гораздо ниже, чем в СССР перед его распадом (Шкаратан, 2011), находясь в русле общемировой тенденции уменьшения доступности для низших социальных слоев высших статусных позиций в обществе (Atkinson, 1995; Krueger, 2012).

Исследователи (Esping-Andersen, 1990) полагают, что высокий уровень социального неравенства в значительной степени определяется неэффективной патерналистской политикой по отношению к низшим социальным группам как со стороны государства, так и частных структур. В рамках данных исследований социальная политика рассматривается не только как основывающаяся на конкретном уровне экономического развития общества, но в значительной степени как предвосхищающая его. 
Некоторыми исследователями (О. Шкаратан, 2011) предлагается увеличить финансирование социальной сферы за счет введения прогрессивного налогообложения и перераспределения экономической власти от высшего к среднему классу, что придаст больший динамизм и устойчивость общественной системе. С другой стороны, исследователи (Григорьев, Павлюшина, 2018: 46) утверждают, что эффективность рынка труда, социальное государство, прогрессивное налогообложение, налоги на наследство не привели к значительному снижению социального неравенства в странах, практикующих данные меры. Однако, согласно исследователям (Acemogly, 2004), социальная политика, направленная на снижение барьеров для вертикальной социальной мобильности и формирование институтов инклюзивного общества способствует ограничению социального неравенства, повышению экономической эффективности и служит одним из стимулов экономического роста.

Следует отметить, что только увеличение финансирования социальной сферы и повышение социальных стандартов не даст ускорения в динамике общественного роста без комплекса мер по развитию форм вертикальной социальной мобильности в рамках формирования комплексной программы сокращения социального неравенства в России.

В различных концепциях открытого общества ставится проблема определения критериев инклюзивного общества и открытости социальной структуры. В рамках данных концепций высокий уровень вертикальной мобильности низших социальных групп отмечается исследователями в качестве одного из основных условий для общества, определяющих его длительный динамичный общественный рост (Норт Д., Уоллис Д., Вайнгаст Б. , 2010).

Гражданское общество в России рассматривается в настоящее время в основном в политическом контексте, с точки зрения его значимости для контроля властных структур со стороны граждан, в тоже время гражданское общество недооценивается в аспекте выполнения важной социальной функции: в качестве одного из основных институтов проведения патерналистской политики. Гражданское общество выступает в европейских странах как некоторая форма государственно-частного партнерства, направленная на эволюцию социальной системы: ограничение роста социального неравенства и стимулирование функционирования социальных лифтов.

Значительный путь, который прошла Россия по пути трансформации своей социальной системы в направлении развития демократических и рыночных институтов, обеспечения национального суверенитета, - не должен приводить к соблазну рассматривать нынешнее состояние российской системы как некоторую постоянную, базовую точку отсчета. Гораздо эффективнее современное состояние российского общества рассматривать как одну из трансформационных точек в направлении большей открытости и стабильности общественной системы.

\section{Выводы.}

- Социальные разрывы, сильное социальное расслоение является критической опасностью российского общества не только препятствующей его развитию, но и создающей опасность непреодолимого отставания от развитых стран в социальной и технологической сфере.

- Уровень социального неравенства закладывается в процессе формирования социальных норм и институтов, включая налоги, вертикальные лифты, толерантность к бедности и т.д. Уровень неравенства после формирования социальных норм и институтов сохраняет свое постоянство, а неэффективные рынки труда и образования, закрытые внешние рынки - это неравенство закрепляют (Barbara, 2012; Hoffman et al., 2002; Григорьев, Павлюшина, 2018: 36).

- С началом рыночных реформ в экономике России была сформирована экономическая модель рыночной экономики, для которой характерна ригидность, очень высокий уровень социального неравенства, несоответствующий высокому уровню развития человеческого капитала в России, и тенденция к увеличивающейся социальной поляризации, что делает невозможным без эволюции социальной системы динамичный экономический рост в долговременной перспективе и сокращение разрыва между уровнем дохода на душу населения в России и развитыми странами.

- В истории периоды высокого уровня социального неравенства предшествовали периодам экономического застоя (Stiglitz, 2013). В данном отношении, существующая на данный момент экономическая модель в России может быть рассмотрена в качестве предпосылки социальной и экономической стагнации.

- Поставленные правительством России задачи догоняющего развития, основанные на преобладании на 2-3\% общемировых темпов развития невозможно решить без решения проблемы сокращения социального неравенства и более полного использования человеческого 
капитала в трансформации и развитии общественной системы. Уровень социального неравенства может быть рассмотрен в качестве одного из основных индикаторов возможности реализации долгосрочного динамичного роста. Согласно оценкам экспертов (Krugman, 2013; Atkinson, 2015; Stiglitz, 2012), сокращение внутреннего социального неравенства, развитие среднего класса приводит к ускорению общественного роста и создает возможности для сокращения уровня межгосударственного неравенства.

- Несмотря на значительные потери человеческого потенциала в результате трансформационных реформ, в России сохраняется возможность успешной реализации моделей догоняющего развития и трансформации существующей социальной модели в направлении уменьшения социального неравенства и увеличения роли среднего класса в социальной структуре.

- Для обеспечения опережающих общемировые темпов общественного роста должна быть сформирована национальная программа, направленная на формирование патерналистских норм и институтов в рамках стратегии патерналистской социальной политики как одного из основных условий общественного роста.

- Снижение общественной поляризации, развитие социальной функции гражданского общества, уменьшение барьеров для вертикальной социальной мобильности, как полагают исследователи (Григорьев, Павлюшина, 2016: 70), должно способствовать трансформации формы социальной структуры российского общества от "латиноамериканской" к "европейской" модели.

Сокращение социального расслоения с помощью патерналистской политики, стратегического планирования, развития гражданского общества, формирования моделей позитивной дискриминации, а также реализаци принципов социального либерализма (Ролз, 1995; Ринген, 2004), направленных на более равномерное распределение общенациональной собственности и дохода, - даст стимул формированию сбалансированной социальной системы и динамичному развитию России в долговременной перспективе.

\section{ЛИТЕРАТУРА}

1. Восленский М. Номенклатура. - London: OPI, 1984, 1990.

2. Григорьев Л. М. (2016). Социальное неравенство в мире - интерпретация неочевидных тенденций // Журнал Новой экономической ассоциации. № 3 (31). С. 160-170. [Grigoryev L. M. (2016). Social inequality in the world — the interpretation of non-evident tendencies. Journal of the New Economic Association, No. 3 (31), pp. 160-170. (In Russian).]

3. Григорьев Л. М., Павлюшина В. А. (2017). Социальное неравенство как проблема экономической стратегии России // Мир новой экономики. No 3. С. 58-71. [Grigoryev L. M., Pavlyushina V. A. (2017). Social inequality as a problem of Russia 's economic strategy. Mir Novoy Ekonomiki, No. 3, pp. 58-71. (In Russian).]

4. Григорьев Л. М., Павлюшина В. А. (2018). Межстрановое неравенство: динамика и проблема стадий развития // Вопросы экономики. No 7. С. 5-29. [Grigoryev L. M., Pavlyushina V. A. (2018). Inter-country inequality in dynamics and the problem of post-industrial development. Voprosy Ekonomiki, No. 7, pp. 5-29. (In Russian).]

5. Григорьев Л., Паршина Е. (2013). Экономическая динамика стран мира в 1992-2010 годах: неравномерность роста // Вестник Санкт-Петербургского университета. Сер. 5: Экономика. № 4. С. 7086. [Grigoryev L., Parshina E. (2013). Economic dynamics of the countries of the world in 1992-2010: Uneven growth. Vestnik SanktPeterburgskogo Universiteta, Series 5: Economics, No. 4, pp. 70 — 86. (In Russian).]

6. Григорьев Л. М., Салмина А. А. (2013). Структура социального неравенства современного мира: проблемы измерения // Социологический журнал. No 3. C. 5-21. [Grigoryev L. M., Salmina A. A. (2013). Structure of social inequality of the modern world: Measurement problems. Sotsiologicheskiy Zhurnal, No. 3, pp. 5-21. (In Russian).]

7. Данканич С. А. Неравенство доходов населения: виды и последствия // Проблемы современной экономики № 3(39), 2011.

8. Деньгуб Ю. Представления о социальной справедливости в контексте современного развития России, "Социология власти", 2004, 120-129с.

9. Норт Д., Уоллис Д., Вайнгаст Б. (2010). Насилие и социальный порядок. Концептуальные рамки для интерпретации письменной истории человечества. М.: Европа. [North D., Wallis J., Weingast B. (2010). Violence and social orders: A conceptual framework for interpreting recorded human history. Moscow: Evropa. (In Russian).]

10. Смольников С. Специфика восприятия населением России понятия социальной справедливости, Вестник ПНИПУ, Социально-экономические науки, 2013, No19 (46), с.104-109.

11. Демченко С., Верещагина А., Самыгин С. Социальная политика и социальная справедливость как индикаторы социальной безопасности России, Гуманитарные, социально-экономические и общественные науки, 2018, No3

12. Кривякина Е. Средняя продолжительность жизни в России вырастет до 76 лет, КП, 12.04.2017// URL: http: //www.kp.ru/daily/26665/3687258/?see-also.number=1373\#see-also 
13. Куликов С. Продолжительность жизни в России выросла до 71,8 года, Российская газета, 29.06.2017//URL: https://rg.ru/2017/06/29/sredniaia-prodolzhitelnost-zhizni-v-rossii-vyrosla-do-719-goda.html

14. Алексей Кудрин не исключает "социального взрыва", если уровень бедности в РФ продолжит расти, Аналитический портал "Newsru.com", 17.06.2019

15. Клименко А., Барабашев А., АКТУАЛЬНЫЙ ОПЫТ ЗАРУБЕЖНЫХ СТРАН ПО РАЗВИТИЮ ГОСУДАРСТВЕННЫХ СИСТЕМ СТРАТЕГИЧЕСКОГО ПЛАНИРОВАНИЯ, ПреПрИНТ WP8/2016/04 (ч. 2) / А. В. Клименко, В. А. Королев, Д. Ю. Двинских, Н. А. Рычкова, И. Ю. Сластихина ; Нац. исслед. ун-т «Высшая школа экономики». - М.: Изд. дом Высшей школы экономики, 2016. - (Серия WP8 «Государственное и муниципальное управление»). -40с. //https://wp.hse.ru/data/2016/11/14/1110320976/WP8_2016_04_Часть2 .pdf

16. Stratfor: Эмиграция из России бьёт рекорды. Кто уезжает из страны?, пер. С. Левитин, аналитический портал "The Insider", 05.07.2016, URL: http://theins.ru/obshestvo/25846 .

17. Медведев Д. А. Социально-экономическое развитие России: обретение новой динамики // Вопросы экономики. 2016. № 10. С. 5-30.

18. Мухаметшина Е. Из России уезжает в разы больше людей, чем учитывает статистика // «Ведомости», 6.10.2016, URL: http://www.vedomosti.ru/politics/articles/2016/10/06/659896-iz-rossii-uezzhaet.

19. Назаров М.. Класс господствующий и обреченный. Интервью с М.Восленским, опубликовано в журнале "Посев", Франкфурт-на-Майне, 1984, 11 № С. 28-33

20. Новопрудский С. Культ нищеброда: ставка на бедных, Газета.ru, 05.07.2019, URL: https://www.gazeta.ru/comments/column/novoprudsky/12473323.shtml

21. Новосельцева Т. ВЫДВИЖЕНЧЕСТВО В КАДРОВОЙ ПОЛИТИКЕ СОВЕТСКОГО ГОСУДАРСТВА в 1920-1930-е годы (на материалах Смоленской области), Автореферат диссертации, Брянск, 2004

22. Седлов Д., Аликина К. Российские миллиардеры богатеют, а Россия — наоборот // РБК, 25.11.2016, URL: https://www.rbc.ru/money/22/11/2016/583469339a7947f801d7631b

23. Рейтинг национальных систем высшего образования, аналитический портал «Гуманитарные технологии», ISSN 2310-1792

24. Ремизов М. Паталогия неравенства, аналитический портал "Эксперт Online, 06.12.2016

25. Ринген С. Распределительная теория экономической демократии, философско-публицистический журнал "Логос", 2004, №2 http://www.magazines.russ.ru/logos/2004/2/ri9.html

26. Ролз Дж. Теория справедливости. (John Bordley Rawls. A Theory of Justice; 1971) Новосибирск, издво НГУ, 1995. — ISBN 5-7615-0365-4.

27. Ромашков А. Интервью Путина FT: экономика, международная безопасность и вопрос о преемнике, BFM.Ru, 28.06.2019

28. Салмина А. Избыточное неравенство и развитие человеческого потенциала. Доклад о человеческом развитии в Российской Федерации. Аналитический центр при Правительстве РФ. М., 2014. С. 84-106

29. Санги Апурва. Редкие кадры: экономику России тормозит дефицит трудоспособного населения, Forbes,26.04.2018//https://www.forbes.ru/biznes/pmef-2018360593-redkie-kadry-ekonomiku-rossiitormozit-deficit-trudosposobnogo-naseleniya

30. Сорокин П. А. Социология революции. - РОССПЭН, 2005. - 704 с. - ISBN 5-8243-0617-6.

31. Стиглиц Дж. Цена неравенства. Чем расслоение общества грозит нашему будущему. М.: Эксмо, 2016.

32. В.Сурков: Долгое государство Путина, Независимая газета, 11.02.2019

33. Средняя продолжительность жизни по странам мира: мужчины, женщины и оба пола, Статистический портал: статистика населения URL: www.statdata.ru/prodolzhitelnost-zhizni-v-stranah-mira

34. Сюй Яньли, Специфика социально-экономических преобразований в Китае, Автореферат диссертации, Заключение, М., 2006.

35. Узбекова А. В Минфине предупредили о серьёзных экономических проблемах // "Российская газета",30 июля, 2016.

36. Шакаратан О. И. Опыт исследования социального воспроизводства в городах СССР/Человеческий фактор в социальном воспроизводстве (Междисциплинарные исследования), М..1987, с.88.

37. Шкаратан О. И., Ястребов Г. А. Сравнительный анализ процессов социальной мобильности в СССР и современной России, Общественные науки и современность, 2011, №2, с.5-28

38. Шаповалов А. Все, кто нажили непосильным трудом. Богатые граждане владеют фактически всеми финансовыми активами и сбережениями в РФ, "Коммерсанть", No65, 12.04.2019,

39. Шерункова О. Дача, машина, курорт: куда исчезает средний класс, Газета.ru, 11.06.2019

40. Шумпетер Й. Капитализм, Социализм и Демократия: Пер. с англ. / предисл. и общ. ред. В. С. Автономова. - М.: Экономика, 1995. — 540 с. — (Экономическое наследие). — ISBN 5-282-01415-7.

41. Acemogly, D., Jonson, S., and Robinson, J. "Institutions as the Fundamental Cause of Long-Run Growth". NBER Working Paper. May 2004. URL: https://www.nber.org/papers/w10481

42. Acemoglu, Daron; Robinson, James A. (2006). Economic Origins of Dictatorship and Democracy. Cambridge University Press. ISBN 9780521855266

43. Atkinson A., Lee Rainwater and Timothy M. Smeeding, Income Distribution in OECD Countries (Paris: Organisation of Economic Cooperation and Development), 1995.

44. Blair Tony (1994) Socialism. Fabian Society, ISBN 0-7163-0565-8 London.

45. "The Economic Bill of Rights". Franklin D. Roosevelt American Heritage Center. Retrieved 10 November 2011.

46. Ferrara P. Is President Obama Really A Socialist? Let's Analyze Obamanomics, Forbes, Dec.20, 2012. 
47. Esping-Andersen, Gøsta (1990). The three worlds of welfare capitalism. Princeton, New Jersey: Princeton University Press. ISBN 9780069028573.

48. Esping-Andersen, Gøsta (1999). Social foundations of postindustrial economies. Oxford New York: Oxford University Press. ISBN 9780198742005.

49. Harrison, Mark. (1999) Soviet industrial production, 1928 to 1955: real growth and hidden inflation. Journal of Comparative Economics, Vol.28 (No.1). pp. 134-155. ISSN 0147-5967

50. Grigoryev L.M., Pavlyushina V.A. Social inequality in the world: trends during 2000-2016 Voprosy Ekonomiki. 2018;(10):29-52. (In Russ.) https://doi.org/10.32609/0042-8736-2018-10-29-52

51. Krueger A. Chairman Council of Economic Advisers. The Rise and Consequenses Inequality, Washington, January 12, 2012

52. Kuznets S. Economic growth and income inequality//American Economic Review. 1955. Vol. 45. No. 1. P. 1-28.

53. The Lancet. Measuring the health-related Sustainable Development Goals in 188 countries: a baseline analysis from the GlobalBurden of Disease Study 2015 - 8.10.2016).

54. Moorsteen R., Prices and Production of Machinery in the Soviet Union in 1928-1958. - Cambridge Mass.: Harvard University Press, 1962

55. Novokmet Filip, Thomas Piketty, Gabriel Zucman, NY, 2017 http://www.piketty.pse.ens.fr //Тома Пикетти. От Советов к олигархам: неравенство и собственность в России 1905-2016, Обзор первого современного исследования о неравенстве в России: Тома Пикетти о том, как оффшоры не только сковывают потенциал экономики, но и скрывают реальный уровень неравенства, "Зеркало"- некоммерческий проект исследования социального неравенства в России //www.rusmirror.ru//18102017

56. OECD. Income Inequality and Poverty. Available at: URL: http://www.oecd.org/social/inequality-andpoverty.htm.

57. OESD, Better Life Index// URL: http://www.oecdbetterlifeindex.org/ru/countries/denmark-ru/

58. Outlook on the Global Agenda (2014). World Economic Forum. Available at: https://www.weforum.org/reports/outlook-global-agenda-2014, accessed 28 February 2018.

59. Piketty T.Capital in the Twenty-First Century, Harvard University Press, 2014, ISBN 9780674430006

60. Rajan R., Zingales L. Saving Capitalism from the Capitalists. Princeton: Princeton University Press, 2004. 369 p.

61. Smith M. Sovereign democracy: the ideology of Yedinaya Rossiya. Defence Academy of the United Kingdom, Conflict Studies Research Centre, 2006

62. Stiglitz, Joseph E. (2012). The Price of Inequality: How Today's Divided Society Endangers Our Future. New York: W.W. Norton \& Company. ISBN 9780393088694. 